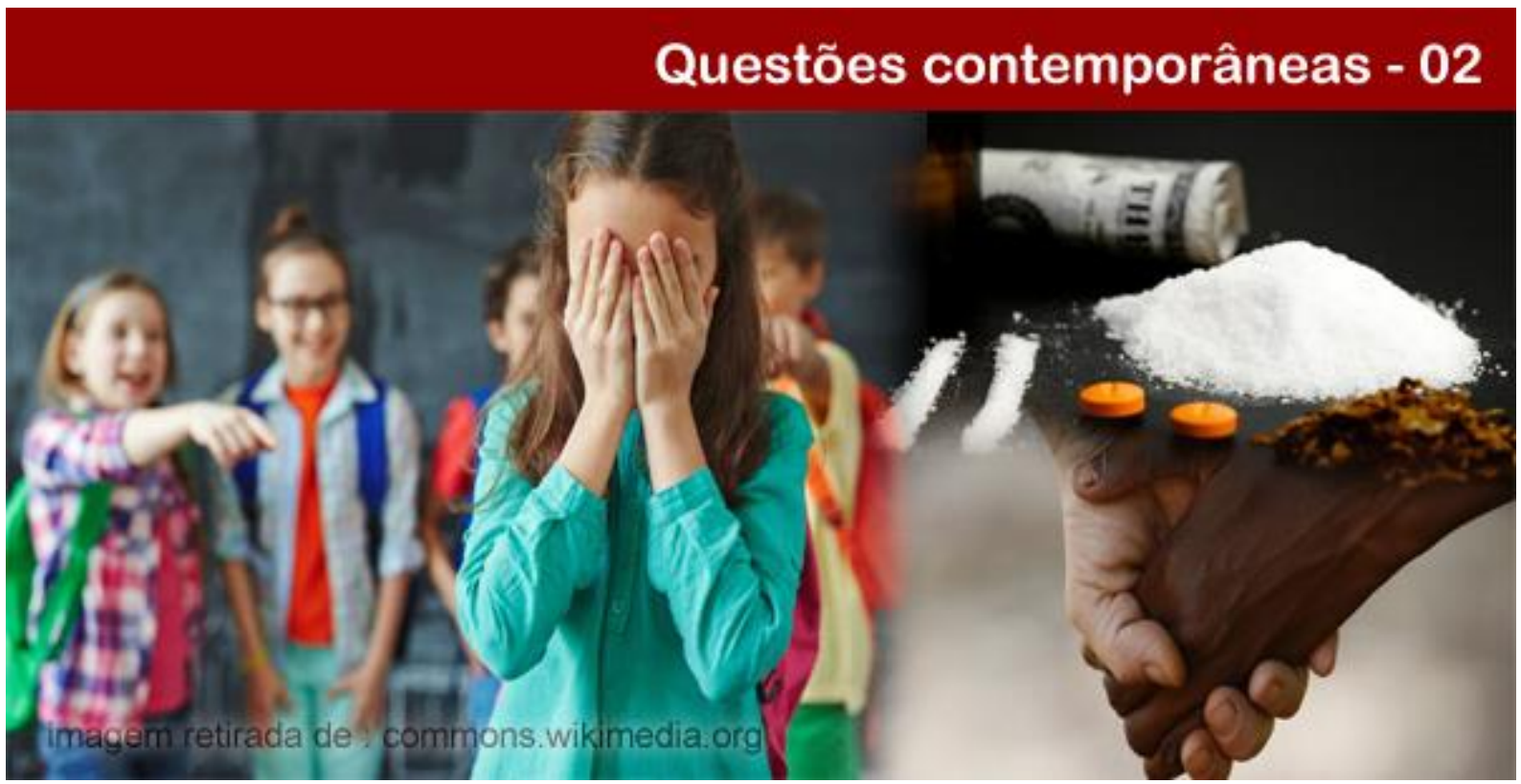

\title{
REPRESENTAÇÕES SOCIAIS DA ESCOLA: UM ESTUDO COM ADOLESCENTES EM ACOLHIMENTO INSTITUCIONAL NO MUNICÍPIO DE PONTA GROSSA/PR ${ }^{1}$
}

\author{
Diana Galone Somer \\ Mestre em Ciências Sociais Aplicadas e Graduada em Serviço Social pela Universidade Estadual de Ponta \\ Grossa (UEPG).E-mail: dianassomer@gmail.com.
}

Constantino Ribeiro de Oliveira Junior

Professor adjunto da Universidade Estadual de Ponta Grossa (UEPG). Doutor em Educação Física pela Universidade de Campinas (Unicamp).E-mail: constantino@uepg.br.

\section{Solange Aparecida Barbosa de Moraes Barros}

Professora adjunta da Universidade Estadual de Ponta Grossa (UEPG). Doutora em Serviço Social pela Pontifícia Universidade Católica de São Paulo (PUC-SP). E-mail: solangemoraesbarros@gmail.com.

Resumo: Este texto refere-se a uma pesquisa realizada com o objetivo de entender as Representações Sociais que as adolescentes acolhidas, em abril de 2016, na Casa Santa Luiza de Marillac e na Associação de Promoção a Menina (APAM), em Ponta Grossa/PR, possuem em relação à escola. As representações sociais estão ligadas ao grupo, no qual os indivíduos compartilham de uma realidade comum a um conjunto social na vida cotidiana. Ainda, a vulnerabilidade e risco social e suas implicações, no plano subjetivo, são estudadas. Posto que, com a família em situação de risco social seus membros podem se encontrar em vulnerabilidade, especialmente a criança e adolescente, e essas situações podem levá-los ao acolhimento. A metodologia empregada para obtenção e análise dos dados foi: pesquisa exploratória; grupo focal; e análise de conteúdo de categorias temáticas. Com base nos resultados da pesquisa, conclui-se que as relações positivas na escola são com os amigos, trazendo um sentimento de pertencimento; enquanto que as relações e interações negativas são com algumas professoras (os) e pedagogas (os), que tem ações que implicam na ocorrência do: bullying, estigma e a alteridade radical. Esses elementos descobertos influenciam na construção da identidade das adolescentes acolhidas. Percebeu-se que as escolas públicas possuem dificuldades no atendimento das crianças e adolescentes que estão em acolhimento.

\footnotetext{
${ }^{1}$ Esta pesquisa tem origem no trabalho de dissertação de mestrado da autora Diana no programa de pósgraduação em Ciências Sociais Aplicadas da Universidade de Ponta Grossa (UEPG).
}

\section{POLÊM!CA $\mid$ LABORE (}

Polêmica - Revista Eletrônica da Uerj - Rua São Francisco Xavier, 524, $1^{\circ}$ andar

bloco D, sl.1001 • Tels.: +55 21 2334-4088/4087 • http://www.e-publicacoes.uerj.br/index.php/polemica/index http://www.labore.uerj.br • laboreuerj@yahoo.com.br 
Palavras-chaves: Alunas/adolescentes acolhidas. Representação social. Escola.

\title{
SOCIAL REPRESENTATIONS OF SCHOOL: A STUDY WITH ADOLESCENTS IN INSTITUTIONAL HOSTING IN THE MUNICIPALITY OF PONTA GROSSA/PR
}

\begin{abstract}
This text refers to a research carried out with the purpose of understanding the Social Representations that the adolescents refuged in April of 2016 in Casa Santa Luiza de Marillac and the Association of Girl Promotion (APAM), in Ponta Grossa / PR, have in relation to the school. Social representations are linked to the group, in which individuals share a reality common to a social set in everyday life. Furthermore, vulnerability and social risk and their implications, on a subjective level, are studied. With the family at social risk, their members may find themselves in vulnerability, especially children and adolescents, and these situations may lead them to refuge them. The methodology used to obtain and analyze the data was: exploratory research; focus group; and content analysis of thematic categories. Based on the results of the research, we conclude that positive relationships in school are with friends, bringing a sense of belonging; while the negative relations and interactions are with some teachers and pedagogues, who have actions that imply in the occurrence of: bullying, stigma and radical alterity. These uncovered elements influence the construction of the identity of the adolescents. It was noticed that the public schools have difficulties in the care of the children and adolescents that are in refuge.
\end{abstract}

Keywords: Students/teenagers in care. Social representation. School.

\section{Introdução}

De acordo com Libâneo (2012), no meio educacional circulam propostas contraditórias em relação às funções da escola, englobando as que solicitam o retorno da escola tradicional e as que optam que ela cumpra missões sociais e assistenciais. Uma ou outra posição revelaria uma tendência concentrada apresentando,

[...] o dualismo da escola brasileira em que, num extremo, estaria a escola assentada no conhecimento, na aprendizagem e nas tecnologias, voltada aos filhos dos ricos, e, em outro, a escola do acolhimento social, da integração social, voltada aos pobres e dedicada, primordialmente, a missões sociais de assistência e apoio às crianças (LIBÂNEO, 2012, p. 16).

Partindo desta reflexão em relação às funções da escola, esta pesquisa trouxe como objetivo entender as Representações Sociais que as adolescentes acolhidas em abril de 2016, na Casa Santa Luiza de Marillac² e na Associação de Promoção a Menina (APAM), possuem em relação à escola. O interesse, em torno desta temática, é em razão da escola ser o espaço onde a adolescente fica boa parte do dia, tanto quando está com os seus familiares ou no acolhimento.

Para tal, é imprescindível explicar alguns pontos quanto ao município de Ponta Grossa, situado no estado do Paraná. O município de Ponta Grossa, em 2016, de acordo com o Instituto Brasileiro de Geografia e Estatística (IBGE), possuía 341.130 mil habitantes. A taxa nacional de crescimento foi de $0,80 \%$ entre 2015 e 2016, dado que em 2015 era de 337,8

${ }^{2}$ No decorrer deste trabalho será utilizada (Marillac) para se referir à instituição Casa Santa Luiza de Marillac.

\section{POLÊM!CA $\mid$ LABORE}

Polêmica - Revista Eletrônica da Uerj - Rua São Francisco Xavier, 524, $1^{\circ}$ andar

bloco D, sl.1001 • Tels.: +55 21 2334-4088/4087 • http://www.e-publicacoes.uerj.br/index.php/polemica/index http://www.labore.uerj.br • laboreuerj@yahoo.com.br 
mil habitantes. A região é denominada "Campos Gerais do Paraná”, expressão consagrada por Maack $(1948)^{3}$. O município de Ponta Grossa dispõe dos serviços socioassistenciais da Proteção Social Básica, especial de média e de alta complexidade, destacadas na Tipificação Nacional de Serviços Socioassistenciais (BRASIL, 2009). Quanto à primeira, Proteção Social Básica, o município possui atualmente 9 Centros de Referência de Assistência Social (CRAS), sobre a proteção especial de média há 4 Centros de Referência Especializado de Assistência Social (CREAS), e de alta complexidade 21 instituições. Sendo que destas 21 instituições, o município conta com cerca de oito Organizações Não Governamentais (ONG) destinadas ao atendimento de crianças e adolescentes em situação de vulnerabilidade e risco social. Assim, percebe-se uma das fragilidades da Política, que é a transferência de programas públicos para o terceiro setor. Raucci (2002) afirma que:

não temos nada contra as ONGs ou contra o fato de empresários do Terceiro Setor
cumprindo o que chamam de função social da empresa dêem dinheiro para o bem da
sociedade a este ou aquele projeto, mas sabe-se que uma das principais
reivindicações do terceiro setor é o desconto de impostos em troca da ajuda que
presta à sociedade! A lógica disso tudo reflete um movimento do neoliberalismo que
busca diminuir o "Custo Brasil" e usa as ONGs para diminuir os gastos públicos,
obrigando-os mediante parcos recursos a contratarem profissionais sob salários
miseráveis ou com contratos de trabalhos temporários ou irregulares porque nunca
se poderá prever se o "terceiro setor" continuará a contribuir com os serviços e se
os manterão segundo critérios técnicos e não políticos. (RAUCCI, 2002, p. 381,
grifo nosso) ${ }^{4}$.

No desenvolvimento deste artigo será apresentada primeiramente a metodologia empregada. Em seguida, o conceito de Representações Sociais na vida cotidiana. Na sequência, serão apresentadas as questões de vulnerabilidade e risco social, além de suas implicações no plano subjetivo e as várias formas de exclusão. Abordar-se-ão, ainda, as dificuldades das escolas públicas com alunos em Acolhimento. Em seguida, será apresentado o percurso metodológico empregado na pesquisa, e os resultados e discussões em torno das representações sociais das adolescentes acolhidas na Marillac e na APAM. Por fim, será apresentada a conclusão com destaque na utilização do Grupo Focal, que proporcionou uma maior compreensão quanto as Representações Sociais das adolescentes acolhidas em relação à escola.

\footnotetext{
${ }^{3}$ Detalhes da identidade histórica e cultural da região dos Campos Gerais. Disponível em: <http://www.uepg.br/dicion/campos_gerais.htm>. Acesso em: 02 mar. 2017.

${ }^{4}$ Nesse seguimento é relevante elucidar que a Casa Santa Luiza de Marillac deixou de acolher as adolescentes, não prestando mais o serviço de acolhimento, desde trinta e um de dezembro de 2016.
}

\section{POLÊM!CA $\mid$ LABORE.}




\section{Metodologia}

A pesquisa aqui apresentada é exploratória. Segundo Gil (1999), as pesquisas exploratórias têm como foco o esclarecimento e modificação dos conceitos; sendo assim, aumentam a experiência em torno de um determinado problema, sucedendo a formulação ou suposição que posteriormente serão estudados.

Entre as oito instituições existentes no município, para o presente estudo, foram escolhidas a Marillac, instituída em 1996, e a APAM, fundada em 1987, uma vez que ambas acolhem adolescentes do sexo feminino que sofreram alguma violação dos seus direitos. Assim, os sujeitos que participaram da pesquisa foram seis adolescentes da Marillac, e sete adolescentes da APAM. Essas adolescentes estão em vulnerabilidade e risco social, criados na maioria dos casos pelos próprios familiares por meio de: violência física, violência psicológica, negligência e violência sexual. A faixa etária das adolescentes em acolhimento na Marillac é de 12 a 18 anos e na APAM é de 4 a 12 anos. Além disso, a construção histórica e a consolidação das duas instituições no atendimento de crianças e adolescentes no município foi o que alicerçou a escolha por ambas as instituições para o universo da pesquisa.

Quando a adolescente acolhida na APAM completa 12 anos, e ainda não houve como retornar ao convívio familiar e comunitário, ela permanece na instituição, de acordo com a determinação da Juíza da Vara da Infância e da Juventude de Ponta Grossa/PR.

Utilizou-se como instrumento metodológico para coleta dos dados o Grupo Focal (GF), que teve a duração de uma hora e meia cada, com duas sessões em cada instituição. A primeira sessão iniciou com as adolescentes desenhando e falando da sua escola, enquanto que a segunda sessão com perguntas voltadas para os relacionamentos e convívio. No decorrer do GF empregou-se uma linguagem acessível para as adolescentes. Foram obedecidas todas as recomendações éticas, tendo sido submetida ao Comitê de Ética em Pesquisa e recebido parecer favorável à sua realização (Parecer $n^{0}$. 110.886/2015).

$\mathrm{O}$ roteiro do GF foi elaborado com doze questões para entender as RS das adolescentes acolhidas em relação à escola. Segundo Gatti (2005, p. 8), o GF é um “[...] bom instrumento de levantamento de dados para investigações em ciências sociais e humanas, mas a escolha de seu uso tem de ser criteriosa e coerente com os propósitos da pesquisa". Para a análise dos dados foi utilizada a técnica de análise de conteúdo de categorias temáticas. De acordo com as etapas propostas por Bardin (2011), realizou-se a pré-análise a partir da leitura

\section{POLÊM!CA $\mid$ LABORE}


flutuante do texto, colhendo as primeiras impressões. Em seguida, fez-se a exploração do material, com a codificação em quantitativo e qualitativo, e por fim, o tratamento dos resultados e a interpretação.

Baseada nas falas das adolescentes elegeu-se como categorias analíticas que possuem representações sociais: relações e interações sociais na escola, bullying, a vida cotidiana no acolhimento/escola e família.

\section{Representações Sociais na vida cotidiana}

A realidade social do indivíduo desempenha um papel constitutivo na origem das representações, enquanto que as Representações Sociais (RS) vão além do “[...] trabalho individual do psiquismo e emergem como um fenômeno necessariamente colado ao tecido social [...] nos fenômenos produzidos pelas construções particulares da realidade social" (JOVCHELOVITCH, 2011, p. 67). Portanto, um agregado de representações individuais não constitui uma RS, sendo necessária uma análise do social enquanto totalidade, ou seja, dos processos de comunicação e vida, já que o social também não é apenas um agregado de indivíduos. Do mesmo modo é importante o entendimento da ligação entre as representações sociais e a vida cotidiana.

Por representações sociais, entendemos um conjunto de conceitos, proposições e explicações na vida cotidiana no curso de comunicações interpessoais. Elas são o equivalente, em nossa sociedade, aos mitos e sistemas de crenças das sociedades tradicionais; podem também ser vistas como a versão contemporânea do senso comum (MOSCOVICI, 1978, p. 181 apud ORNELLAS, 2012, p. 122, grifo nosso).

Portanto, de acordo com Ornellas (2012, p. 12), a abordagem de Moscovici e Jodelet, é que a "[...] representação social é um conhecimento do senso comum e é formada em razão do cotidiano do sujeito". Nesta perspectiva, Ornellas (2012) garante que

É uma abordagem que se encontra hoje no centro de um debate interdisciplinar, na medida em que se tenta nomear, fazer relações entre as construções simbólicas e a realidade social. As representações sociais dirigem seu olhar epistêmico para entender como esta realidade constrói a leitura dos símbolos presentes no nosso cotidiano (ORNELLAS, 2012, p. 121).

Neste sentido, Sá (2004) explica que um desafio encontrado por Moscovici ao formular a teoria, foi situar com efetividade a psicologia e as ciências sociais, um campo de saber específico, mas não autônomo, para ocupar de fato esse território onde se desenvolvem fenômenos de dupla natureza. Por isso, Sá (2004) afirma que existe um vasto campo de

\section{POLÊM!CA $\mid$ LABORE}

Polêmica - Revista Eletrônica da Uerj - Rua São Francisco Xavier, 524, $1^{\circ}$ andar

bloco D, sl.1001 • Tels.: +55 21 2334-4088/4087 • http://www.e-publicacoes.uerj.br/index.php/polemica/index

http://www.labore.uerj.br • laboreuerj@yahoo.com.br 
estudos psicossociológicos em relação às "representações sociais" e que o problema está na constituição dos objetos do conhecimento psicossociológicos, e não nos fatos ou fenômenos.

Jodelet (1984, p. 36 apud SÁ, 2004, p.24) esclarece que, no que se referem às RS, “o fato de que se trate de uma forma de conhecimento acarreta o risco de reduzi-la a um evento intraindividual, onde o social intervém apenas secundariamente [...]". Além disso, "o fato de se tratar de uma forma de pensamento social acarreta o risco de diluí-la nos fenômenos culturais ou ideológicos". A partir dessa afirmação sobre os riscos, Sá (2004, p. 24) traz um questionamento de "[...] como situar o conhecimento mobilizado pelas pessoas comuns, na comunicação informal da vida cotidiana”. Em seguida, o mesmo autor elenca os assuntos e objetos sociais na atualidade, que são: meninos de rua, pivetes, trombadinhas; a violência urbana e a insegurança do cidadão; o tráfico de drogas, o crime organizado; os grupos de extermínio; o arbítrio policial, e ainda os que se aproxima da pesquisa que são: as desigualdades sociais e educacionais; a pobreza, a marginalidade.

Cabe pontuar que de acordo com Sá (2004, p. 25), a lista ainda está incompleta, e sua apresentação teve a intenção de ilustrar a quantidade e a "[...] extrema diversidade de assuntos que nas relações interpessoais do dia-a-dia, prendem a atenção o interesse e a curiosidade das pessoas, demandam sua compreensão e forçam seus pronunciamentos". A explicação destes objetos sociais vai além de simples opiniões isoladas, a respeito das atitudes e dos assuntos. Ela articula e combina com diferentes questões ou objetos, com uma lógica própria.

De outra forma, Jodelet (2001) explica que as RS são "fenômenos complexos" que são ativados continuamente na vida social. Jodelet (2001, p. 22) elucida que a comunidade científica está de acordo quanto às RS serem "[...] uma forma de conhecimento socialmente elaborada e partilhada, com um objetivo prático, e que contribui para a construção de uma realidade comum a um conjunto social". Isto concorda com o já estabelecido por Moscovici (2011), que afirma que as RS se constroem por intermédio do processo comunicativo e no convívio de pessoas, deixa de ser subjetiva e passa a ser intersubjetiva, ou melhor, as pessoas buscam o consenso (conformidade de opiniões) e deste modo as RS têm um sentido prático.

Para Jodelet (2001) as RS devem ser estudadas através da articulação entre os elementos afetivos, mentais e sociais. Para, assim, integrar ao lado da cognição, da comunicação e da linguagem, “[...] a consideração das relações sociais que afetam as representações e a realidade material, social e ideativa sobre a qual elas têm de intervir"

\section{POLÊM!CA $\mid$ LABORE}


(JODELET, 2001, p. 26). Desse modo partilhamos esse "[...] mundo com os outros, que nos servem de apoio, às vezes de forma convergente”, em outros momentos pelo conflito, “[...] para compreendê-lo, administrá-lo ou enfrentá-lo. Eis porque as representações são sociais e tão importantes na vida cotidiana" (JODELET, 2001, p. 17, grifo nosso). As RS guiam para definir os diferentes aspectos da realidade do dia a dia, no modo de tomar decisões, de interpretar esses aspectos e, eventualmente, colocar-se frente a eles de forma defensiva.

\section{Vulnerabilidade e risco social: implicações}

A vulnerabilidade social é muitas vezes associada diretamente a condições de pobreza e miserabilidade e, assim, demonstradas através de índices socioeconômicos. A pobreza é, sem dúvida, um dos grandes pilares nos quais se assentam diversas situações de vulnerabilidade social da sociedade capitalista, uma vez que produz a exclusão da população em relação a políticas e serviços públicos. Além disso, afeta diretamente a garantia de direitos e cidadania (TOSSORIAN; RIVERO, 2014, p. 57)

Gabatz (2015) clarifica que a vulnerabilidade social passou a receber maior atenção nos países desenvolvidos e em desenvolvimento nos últimos anos. Monteiro (2011) explica que na procura dos elementos que deram origem ao conceito de vulnerabilidade social, ficou evidente que este foi “[...] gestado nos organismos internacionais como sendo uma alternativa ao conceito de exclusão social, sendo amplamente difundindo como orientação para intervenção dos gestores na consolidação de políticas públicas” (p. 36).

Segundo Brito e Veiga (2016), há um consenso dos vários conceitos averiguados em relação à vulnerabilidade social, diretamente relacionada “[...] com a exclusão social, ou seja, trata-se da incapacidade do indivíduo de controlar as forças que afetam seu bem-estar, bem como aproveitar as oportunidades propiciadas pelo Estado, pelo mercado ou pela sociedade" (p. 2).

A vulnerabilidade social está presente no plano subjetivo, uma vez que é no sujeito que se apresenta as várias formas de exclusão, a qual é vivida como carência, emoção e necessidade do "eu"5 (SAWAIA, 2001). O indivíduo não é responsável por sua situação social, e em vista disso, por si mesmo, não é capaz de superá-la. Confirmando essa

\footnotetext{
${ }^{5}$ Sawaia (2001) esclarece que, o que importa é a sobrevivência "específica, com reconhecimento e dignidade. Mesmo na miséria, eles [o desejo e a ética] não estão reduzidos às necessidades biológicas, indicando que não há um patamar em que o homem é animal. [...] O brado angustiante do 'eu quero ser gente' perpassa o subtexto de todos os discursos" (SAWAIA, 2001, p. 115-116).
}

\section{POLÊM!CA $\mid$ LABORE}


perspectiva, Aguiar (2011, p. 131) elucida que “[...] cabe ao pesquisador o esforço analítico de ultrapassar essa aparência (essas formas de significação) e ir em busca das determinações (históricas e sociais), que se configuram no plano do sujeito", nas suas necessidades, motivações e interesses que são individuais e históricos, para atingir o sentido atribuído/constituído pelo sujeito.

De acordo com Sawaia (2001), o indivíduo sofre, porém, o sofrimento não tem origem nele, e sim em "intersubjetividades delineadas socialmente”. Diante disso, o sofrimento éticopolítico

[...] retrata a vivência cotidiana das questões sociais dominantes em cada época histórica, especialmente a dor que surge da situação social de ser tratado como inferior, subalterno, sem valor, apêndice inútil da sociedade. Ele revela a tonalidade ética da vivência cotidiana da desigualdade social, da negação imposta socialmente às possibilidades da maioria apropriar-se da produção material, cultural e social de sua época, de se movimentar no espaço público e de expressar desejo e afeto. (SAWAIA, 2001, p. 104-105).

Para conhecer o sofrimento ético-político, é necessário fazer uma análise das formas "[...] sutis de espoliação humana por trás da aparência da integração social” (SAWAIA, 2001, p. 106). Nesse sentido, Ferrari e Kaloustian (2004, p. 13) afirmam que “[...] por detrás da criança excluída da escola, nas favelas, no trabalho precoce urbano e rural e em situação de risco, está a família desassistida ou inatingida pela política oficial”.

Ferrari e Kaloustian (2004) explicam que a situação da família se caracteriza por problemas sociais de naturezas diversas como: exploração e abuso, atentados frequentes aos direitos humanos, barreiras sociais, econômicas e culturais que afetam ao desenvolvimento integral de seus membros. Os mesmos autores elucidam que uma das situações de vulnerabilidade das famílias é a questão migratória. Esta ocorre por motivos de sobrevivência, causando a desestruturação do espaço doméstico. Eles esclarecem também que o domicílio das famílias está ameaçado frequentemente pela “[...] degradação do meio ambiente: o acesso aos serviços urbanos básicos, aos recursos produtivos e aos diferentes métodos de planejamento familiar problemático" (2004, p. 13). Estas questões sobrevêm e afetam especialmente as famílias em situação de pobreza e risco e vulnerabilidade social. É importante elucidar que as medidas de proteção especial direcionam-se aqueles (as) que se encontram em situação de risco social e pessoal, principalmente crianças e adolescentes.

\section{POLÊM!CA $\mid$ LABORE}


Segundo Gomes e Costa (1993, p. 20 apud HILLESHEIM; CRUZ, 2014, p. 76), “[...] neste caso, essas medidas não se referem ao universo da população infanto-juvenil, mas se voltam, especificamente, para a chamada infância em situação de risco [...]”, ou seja, para aquelas crianças e adolescentes que se encontram em situações particularmente difíceis na vida. A infância em situação de risco, segundo as autoras, está vinculada a fatores que ameacem ou causem dano à integridade física, psicológica da criança ou adolescente, sendo decorrência da omissão ou ação de diversos agentes como: "família, outros grupos sociais ou o próprio Estado". Em vista disso, os motivos que as levam ao acolhimento ${ }^{6}$ em instituição de longa permanência ${ }^{7}$ estão relacionados à situação de vulnerabilidade e risco social no qual se encontram, bem como ao processo socioeconômico.

Neste sentido, o impacto do Estado através de suas políticas econômicas e sociais afeta diretamente as famílias, e, consequentemente, produzem impacto direto nas crianças e adolescentes.

\section{Escolas públicas e as dificuldades com alunos em acolhimento}

As políticas oficiais para a escola em "nosso país se apresentam hoje em duas orientações curriculares complementares, subordinadas à lógica das políticas de contenção da pobreza, atendendo às estratégias de manter a competitividade no contexto da globalização e da diversificação dos mercados" (LIBÂNEO, 2016, p. 49). Por esse motivo, as medidas adotadas pelas políticas oficiais para os problemas educacionais são soluções evasivas segundo Libâneo (2012). Isso ocorre pelos desacordos entre legisladores, educadores e pesquisadores em relação aos objetivos e as funções da escola, ou ainda pela orientação dos organismos internacionais exercidas quanto à educação e ao ensino.

Quando o adolescente é acolhido ocorre a transferência da escola, próxima de sua casa, para estudar próximo da instituição. Assim, somam-se aos problemas destacados, as dificuldades no cotidiano escolar próprias de alunos em acolhimento, posto que eles precisam se adaptar às normas internas da nova escola, bem como às normas da instituição de

\footnotetext{
${ }^{6}$ Nos últimos 20 anos, ocorreram distintas transformações na concepção da modalidade de proteção chamada abrigo, desde a reordenação resultante da implementação do Estatuto da Criança e do adolescente (ECA) à sua inclusão de forma pronunciada na Política de assistência social.

${ }^{7}$ São destinados, por exemplo, às crianças, aos adolescentes, aos jovens, aos idosos, às pessoas com deficiência e às pessoas em situação de rua que tiverem seus direitos violados e/ou, ameaçados e cuja convivência com a família de origem seja considerada prejudicial a sua proteção e ao seu desenvolvimento (BRASIL, 2005, p. 37).
}

\section{POLÊM!CA $\mid$ LABORE}


acolhimento. As relações e interações sociais das instituições de acolhimento com as escolas públicas, de acordo com o estudo de Buffa e Teixeira (2011 apud SERIKAWA, 2015), apresentam algumas dificuldades:

[...] os funcionários da entidade acolhedora declararam que o fato das crianças serem abrigadas fazia com que fossem tratadas com atitudes preconceituosas $e$ excludentes pelos professores e demais funcionários da escola, como era também a explicação para a causa do fracasso escolar desses alunos. As autoras indicaram também que a própria entidade de acolhimento falha, permanecendo omissa e não atuando como facilitadora da inclusão dessas crianças por também internalizar o estigma social instituído. (BUFFA, TEIXEIRA, 2011 apud SERIKAWA, 2015, p. 31, grifo nosso).

Batista e Almeida (2008) explicam que se depara com docentes com uma visão préconcebida, às vezes parcial, da realidade e da demanda de discentes em vulnerabilidade. Essa visão traz um universo que gera o distanciamento entre acolhimento-escola e, consequentemente, desta com os alunos acolhidos, criando um abismo nas relações de ensinoaprendizagem.

Silva Santos (2009) complementa, afirmando que o desconhecimento em relação à medida de acolhimento institucional, por parte da escola e de seus profissionais, impede a inclusão efetiva de crianças e adolescentes.

Deste modo, Santos (2006, p. 102) exemplifica que "[...] o objeto tem uma realidade per se, que vem da sua constituição material. Um objeto tomado isoladamente tem um valor como coisa, mas o seu valor como dado social vem de sua existência relacional". Por isso, a escola pode ser entendida como espaço geográfico que se constitui de diversas formas e objetos, cujos valores, conteúdos e significados são socialmente determinados pelos diversos sujeitos que ali convivem.

Nessa conjuntura, de acordo com Souza (1995), a instituição escolar apresenta-se no seu cotidiano com inúmeras práticas e compartilhamentos de culturas e ideias. E como as ações cotidianas são dinâmicas, visto que se diferenciam um dia do outro, a escola com certeza convive no seu cotidiano com novidades, medos e angústias. Portanto, a escola e acolhimento institucional precisam trabalhar em rede, para atender a nova realidade, que, segundo Gonçalves e Guará (2010, p. 11), é mais “complexa e multifacetada, tem provocado mudanças na forma como a sociedade se organiza: a articulação em parcerias e redes é um desses novos arranjos que afloraram fortemente nos últimos anos", de tal modo que, para

\section{POLÊM!CA $\mid$ LABORE}


atender a demanda da população, tem se mesclado as ações de órgãos de governo, sociedade civil organizada, assim como das empresas privadas.

\section{Resultados e discussões}

Essa pesquisa não se refere a um adolescente "genérico" ou "comum", mas a um adolescente específico, aquele que se encontra em vulnerabilidade e risco social. O entendimento da "adolescência" no contexto sócio-histórico é fundamental, de acordo com Lírio (2012), pois essa concepção não se inquieta em perguntar "o que é adolescência", mas em estudar como ela é construída. Essa contradição vivida pelos jovens, a partir da sociedade capitalista gerada por questões de ingresso no mercado de trabalho e extensão do período escolar, de acordo com Bock (2007), originou uma série de características, que refletem "a nova condição social" que se encontram. A psicologia as descreve não como sendo naturais, mas que são constituídas no processo histórico e social: tendência grupal, atitude rebelde, crises de identidade e busca de si mesmo, necessidade de intelectualizar e fantasiar, onipotência e entre outras.

Portanto, o contexto sócio-histórico das adolescentes acolhidas na Marillac e na APAM aparecerá direta ou indiretamente nas suas falas. É importante destacar que participaram desta pesquisa 13 adolescentes acolhidas, sendo seis da Marillac: Zoe, Lyly, Megan, Kate, Freya e Alice, e sete da APAM: Elza, Lucy, Ruby, Amélia, Jade, Leah e Emma. Para assegurar o anonimato das adolescentes e devido ao fato delas gostarem de filme, utilizou-se para cada uma o nome fictício de uma personagem de um longa-metragem.

Serão destacados em seguida alguns recortes das falas das adolescentes considerados relevantes para a discussão. As falas surgiram no desenvolvimento do Grupo Focal, o tema discutido foi a escola, e foram evidenciadas a partir da análise de conteúdo temáticacategorial as categorias: a vida cotidiana no acolhimento/escola e família; as relações e interações sociais na escola; e bullying.

A primeira categoria destacada é a vida cotidiana no acolhimento/escola e família. A vida cotidiana é heterogênea em vários aspectos, mas, segundo Heller (2004), principalmente no que se refere à significação e conteúdo, ou a relevância dada aos tipos de atividades. Quanto às atividades são: a organização do trabalho e da vida privada, a social sistematizada, os lazeres e o descanso, a purificação e o intercâmbio.

\section{POLÊM!CA $\mid$ LABORE}


Apresentam-se, então, neste momento, as representações sociais da vida cotidiana das adolescentes das instituições pesquisadas, no contexto vivenciado no acolhimento/escola e na família. Na APAM, a adolescente Leah relata sua dificuldade de ler e afirma que não vai para o reforço por estar no acolhimento. Enquanto que Lucy fala por todas as adolescentes ao assegurar que elas não vão fazer os trabalhos com os amigos na escola.

Moderadora- O que você não gosta na escola?

Leah- Perder o recreio porque tava copiando. Eu não sei ler.

Moderadora- Você tem reforço?

Leah-Só têm de tarde, as meninas (Serviço de convivência e Fortalecimento de Vínculos) vão, eu não porque estou na instituição, eu estudo de manhã.

Moderadora- Como você se sente morando aqui na APAM?

Lucy- [...] Muita coisa assim sabe, pra fazer trabalho com os amigos a gente não vai. A gente é tratada diferente porque a gente não pode, não sei o quê. Daí falam muito a APAM, a APAM.

Neste seguimento, Guará (2006, p. 71) elucida que um programa de acolhimento institucional dever ser capaz de "contemplar a complexidade das questões que envolvem a responsabilidade de educar e proteger [...]" crianças e adolescentes, bem como suas famílias, visto que se encontram na maioria das vezes em grande vulnerabilidade e sofrimento. A adolescente Lucy traz em sua fala a dificuldade que a escola e o acolhimento possuem no atendimento.

Lucy- Quando aconteceu de falarem que as tias vão levar vocês pra escola, fui uma das meninas que fiquei "pê" da vida. Porque eu voltava certo da escola e pra casa (APAM). Eu era a primeira a chegar na APAM, eu nunca vinha com as meninas. Uma porque eu sentia vergonha do jeito que elas andavam, elas faziam muita algazarra na rua.

Lucy - As mães sociais levam e trazem e isso é muito constrangedor pra gente (as outras adolescentes balançam a cabeça confirmando), que além de falarem da APAM, não, assim, eu acho até bacana a tia buscar a gente, mas é o negócio assim, do uniforme da APAM tudo rosa e tá escrito o símbolo a APAM. Então acho que não é por que a gente é da Casa Lar (APAM) que eles deviam entregar o bilhete para as mães sociais, devia entregar pra mim.

Apreendeu-se que existe uma representação negativa, com base nas falas das adolescentes, quanto à relação do acolhimento com a escola, que afeta diretamente o cotidiano escolar. São esses momentos de dificuldade e problemas que, em longo prazo, Moscovici (2011, p. 51) assegura que criam "nós de estabilidade e recorrência, uma base comum de significância [...]”; isso fornece uma base comum para as representações. Percebe-se, assim,

\section{POLÊM!CA $\mid$ LABORE}

Polêmica - Revista Eletrônica da Uerj - Rua São Francisco Xavier, 524, $1^{\circ}$ andar

bloco D, sl.1001 • Tels.: +55 21 2334-4088/4087 • http://www.e-publicacoes.uerj.br/index.php/polemica/index

http://www.labore.uerj.br • laboreuerj@yahoo.com.br 
que a escola tem dificuldades no atendimento das crianças e adolescentes que vivem nos acolhimentos.

Outro ponto de dificuldade encontrada pela escola, bem como pelo acolhimento, que foi observado, é trazer a família e familiares do adolescente acolhido, que se encontra ausente dos dois ambientes, para que participe das atividades das duas instituições. Segue o relato das adolescentes da Marillac,

\footnotetext{
Moderadora- Você tem mais alguma coisa para falar da Marillac? vindo.

Moderadora- Você gosta de morar aqui Megan?

Megan- Não.

Moderadora- Você não gosta daqui, por quê?

Megan- Porque eu queria ta morando junto com a mãe.

Moderadora- Por quê?

Megan- Tenho saudade.
}

Zoe- Tenho dificuldade de ver meus familiares, é o que mais tenho dificuldade, porque eles são usuários de drogas e tal. Daí complica de eu ir lá, e eles acabam não

Na APAM:

Moderadora- Como você sente morando aqui na APAM?

Leah- Ruim, longe da mãe.

A partir das falas das adolescentes Zoe, Megan e Leah, percebeu-se que ambas sofrem com a ausência dos familiares. Mas é relevante mencionar que as observadoras notaram, após estas respostas, que mesmo as adolescentes que não expressaram pela fala a ausência da família, ficaram em prolongado silêncio, sendo difícil para a moderadora retomar a conversa sobre este tópico. Segundo Bardin (2011), o que ocorreu está ligado à inferência, que é a profundidade nos discursos (fala de Zoe, Megan e Leah), que são os significados que podem estar explícitos ou ocultos.

A segunda categoria analítica refere-se às relações e interações sociais na escola. Para Santos (2016), o processo de aprendizagem precisa contemplar os aspectos afetivos, cognitivos, sociocultural e da comunicação, indissociáveis, porque as fontes de informação, de investigação e de solução de problemas não são adquiridas apenas nas experiências escolares. Elas acontecem, conforme o autor, essencialmente na "[...] interação do sujeito com o ambiente, com as experiências de vida e com a sua cultura" (p. 9, grifo nosso).

\section{POLÊM!CA $\mid$ LABORE}


Logo, apresentam-se as RS positivas das adolescentes quanto aos amigos. Com base nas respostas da quinta pergunta "com quem você conversa na escola?", nos recortes, as adolescentes da Marillac relatam:

Alice- Minha amiga $^{8}$, todo mundo tem amiga;

Lyly- Com minhas amigas.

Kate- Com as minhas amigas.

Freya- Converso mais com minha amiga.

Zoe- Eu converso com, no caso com o meu grupinho de amigo, a maioria são meninos, mas tem algumas meninas.

Megan- Com as meninas, minhas amigas.

Na APAM:

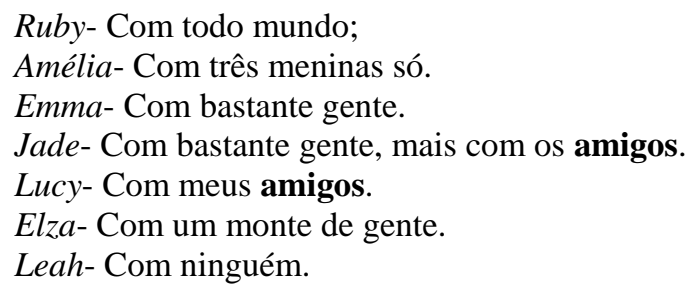

Nas falas da maioria das adolescentes da Marillac e da APAM, elas trouxeram somente as colegas/amigas (os) e não tiveram lembrança dos funcionários, professores, pedagogas, quando se perguntou com quem você conversa na escola. Por essa razão, ficou claro que os amigos possuem um papel significativo na vida cotidiana das adolescentes, nas relações e interações sociais.

A terceira categoria analítica é o bullying. Segundo Stefano (2014), alguns estudos apontam que o bullying pode acontecer por meio: moral (discriminar, difamar, caluniar); verbal (zoar, apelidar, xingar,); psicológico (intimidar, ameaçar, perseguir); sexual (abusar, assediar, insinuar); virtual (mensagens de celular e internet); e material (roubar, furtar, destruir).

Entretanto, o bullying apresentado neste estudo vai além dos destacados na literatura; isso pode ser visto na sequência, nas falas em torno do estigma e alteridade radical. Esses são praticados por professores, pedagogas e alunos na relação e interação com as adolescentes da APAM, pois estes apresentaram e compartilharam da RS negativa em relação aos mesmos.

Trazem-se inicialmente as falas das adolescentes Freya e Leah, ao responder a décima segunda pergunta: Como você sente-se morando na Casa Santa Luiza de Marillac?

${ }^{8}$ Será omitido o nome das amigas das adolescentes.

\section{POLÊM!CA $\mid$ LABORE}

Polêmica - Revista Eletrônica da Uerj - Rua São Francisco Xavier, 524, $1^{\circ}$ andar

bloco D, sl.1001 • Tels.: +55 21 2334-4088/4087 • http://www.e-publicacoes.uerj.br/index.php/polemica/index

http://www.labore.uerj.br • laboreuerj@yahoo.com.br 
Moderadora- Tem mais alguma coisa que você queira falar sobre a casa?

Freya- Sim. Todo mundo na escola fica falando, ah você não tem mãe, por isso que você mora no abrigo (acolhimento). Por isso, que eu bati no piá ${ }^{9}$ hoje na escola. Quando eu chego lá (escola) uma menina me contou, bem amiga minha. Ela me contou que outra (colega) não queria que eu fosse porque eu sou do abrigo (acolhimento).

Moderadora- Essa colega falou alguma coisa pra você?

Freya- Ela disse que aqui quem vem é maconheiro essas coisas, eu falei pra ela que não é assim, aqui a gente tá por precisão. A gente não ta porque a gente não tem mãe e não tem pai, é por precisão. E ela bem assim, só vai lá (Marillac) quem é maconheiro e bandido. Daí eu não falei para a professora porque daí ia dar confusão. Eu falei para as meninas lá se elas não quiserem ficar perto de mim, por mim não dá nada.

Moderadora- E os professores?

Freya- Tratam bem, é só as meninas metidinhas que fazem bullying por eu estar no abrigo.

[Freya relatou ter dificuldades em se relacionar com os amigos (as). Acabou agredindo um colega que a rotulou como "sem mãe". Também que tem colegas que não conversam com ela por estar no acolhimento (bullying)].

Na APAM, a questão do bullying surge com a pergunta:

Moderadora- Você gosta de ir para a escola?

Leah- Não.

Moderadora- Por quê?

Leah- Porque, porque, porque só tem pia chato, daí se a gente fala com uma menina ele pensa que é dele, depois manda a gente calar a boca, eu mando ele calar a boca também. Depois vira uma confusão, ele vai e fala pra mãe, daí eu pego e converso com a tia (a tia que é funcionária é mãe do colega), e falo a verdade, e daí ele fala com a mãe dele de novo, é assim.

Quanto à fala da adolescente Freya da Marillac, fica evidente que o bullying (moral com a discriminação) que sofre é por estar em abrigo/acolhimento, sendo rotulada por ter um contexto sócio-histórico diferente. Tem-se o preconceito, e como consequência a discriminação e o distanciamento dos colegas, sendo construído o estigma. Enquanto que na fala de Leah, está disfarçado no seu mau relacionamento com os meninos, mas fíca claro quando afirma que não tem amigos na escola em outros momentos. Tanto Freya como Leah vivenciam o preconceito, que é formalizado nas relações e interações com os colegas na forma de discriminação, tendo o julgamento de pessoas piores e melhores, inferiores e superiores. Essa situação mexe com todo o sistema de representações e valores que vão sendo construídos nas adolescentes.

9 Piá: gíria do Sul do Brasil, criança ou adolescente do sexo masculino, disponível em: <http://pt.girias.wikia.com/wiki/Pi\%C3\%A1>. Acesso em: 10 jun. 2018.

\section{POLÊM!CA $\mid$ LABORE}

Polêmica - Revista Eletrônica da Uerj - Rua São Francisco Xavier, 524, $1^{\circ}$ andar

bloco D, sl.1001 • Tels.: +55 21 2334-4088/4087 • http://www.e-publicacoes.uerj.br/index.php/polemica/index

http://www.labore.uerj.br • laboreuerj@yahoo.com.br 
$\mathrm{Na}$ Marillac, apenas duas adolescentes relataram sofrer o bullying: Freya pelos colegas, diretamente, e Zoe pela professora, indiretamente, no ambiente escolar. Esta última, na mesma pergunta, diz:

Zoe- Eu me sinto ao mesmo tempo protegida, e me sinto presa, mas no restante vou levando (adolescente diminui a tonalidade da voz).

Moderadora- Tem mais alguma coisa?

Zoe- [...] Quando eu falo (para os colegas): Eu moro na Marillac! Me olham assim (silêncio). Mas lá não é para marginal! Eles rotulam, né, quem mora em abrigo, daí olham assim para mim. Você mora lá, daí não entendem né, mas eu não acabo sofrendo não. Não sei os professores, eu sei que alguns sabem, mas eles são tranquilos, e a menina que eu ando também, só tem um espanto. Eu perguntei para uma professora, ela nem sabia que eu estava no acolhimento. A professora disse: Porque, lá a gente vê as meninas da Marillac como meninas sapatonas, meninas briguentas, mas eu olhando pra você eu não vejo nada. Mas eu falei, mas é às vezes e pra isso que eu to aqui, para mostrar que não é assim a Marillac, que acabou isso. Daí a irmã falou é porque antigamente tinha umas meninas bem barra pesada. É, mas agora não tem. Elas não tão rotulando mais né? Por serem mais adultos, acho que eles não fazem isso.

O que gera o estigma é o preconceito, ambos naturalizam e promovem palavras e ações violentas (GOFFMAN, 1988). As outras adolescentes da Marillac não compartilharam dos relatos de Freya e Zoe. Talvez alguns fatores tenham dificultado, como: Kate e Lyly terem sido acolhidas há apenas dois dias antes da primeira sessão do GF e ainda não saberem em qual escola e horário iriam estudar; e Alice e Megan receberem atendimento psicológico. Eles talvez tenham impedido ou bloqueado que as adolescentes trouxessem em suas falas o bullying (preconceito) e o estigma. Isto não significa que não seja vivido, mas não foi problematizado, de modo que não se construiu tal Representação Social.

$\mathrm{Na}$ APAM, quanto a décima segunda pergunta ("como você se sente morando na APAM?"), obteu-se o seguinte relato:

Moderadora- Tem mais alguma coisa que queira falar da APAM?

Emma- Sim, porque nós chegamos atrasadas na escola, a pedagoga falou vocês são uns anjinhos, até as asas crescem, né. Ela xingou todas nós da Casa Lar (APAM), ela fala cada coisa que... (silêncio).

Moderadora- Ela trata assim, só vocês?

Emma- A gente é diferente, ela não fala o nosso nome, ela fala as meninas da APAM. Só que eu acho que a gente é igual a todo mundo, ano passado tinha piá de abrigo e eles não falavam.

Jade- Eu acho que sim, porque normalmente este tempo a gente ia vir embora mais antes. Não só por causa só de mim, daí ela (pedagoga) chegou em todas e falou assim, quem é, falou meu nome e depois da APAM, daí eu fiquei: nossa que vergonha né, daí eu falei eu. Ela disse, então vai que a tia da APAM está esperando. Então tá bom. Tipo dá um constrangimento, sabe? Então é meio difícil conviver com isso, não, nada ver assim, mas eles podiam chamar nós pelo nome, né?

\section{POLÊM!CA $\mid$ LABORE}

Polêmica - Revista Eletrônica da Uerj - Rua São Francisco Xavier, 524, $1^{\circ}$ andar

bloco D, sl.1001 • Tels.: +55 21 2334-4088/4087 • http://www.e-publicacoes.uerj.br/index.php/polemica/index

http://www.labore.uerj.br • laboreuerj@yahoo.com.br 


\begin{abstract}
Ano passado a gente tava assim com nossos amigos conversando né, em vez dela entrar e falar na rodinha, ela falava assim, o meu nome e depois falou APAM, vai pra fila, a gente ficava meio constrangido. Quase todo mundo sabe que a gente é da APAM. Não precisa ficar falando, eu fico constrangida.

Lucy- Ano retrasado quando tinha umas outras meninas aqui (APAM), que elas estudavam, e ainda estudam lá né, tinha meninas lá na frente do sexto ano fazendo bagunça que era da APAM, as meninas da APAM querem parar de fazer bagunça. Sendo que tinham outras lá atrás não fazendo bagunça e as outras fazendo sabe. (Lucy quis dizer que algumas meninas da APAM não faziam bagunça e a pedagoga generalizou)

Os meus amigos só perguntam o que a gente faz, essas coisas. Mas o bullying que eu acho é dos professores, principalmente da pedagoga, quando vai chamar a gente quando é para sair mais cedo ou qualquer coisa assim, e ela não acha. Ela fala: Tem alguma menina da APAM aqui? Daí sabe, a gente fica constrangida, né. Porque não é legal a gente morar num abrigo (acolhimento). Falar: Eu moro num abrigo (acolhimento), as meninas (amigas) falam: Você tem celular, mas não dá para usar. Daí fica aquele negócio: Ah, então você mora na APAM! Muita coisa assim sabe, pra fazer trabalho com os amigos a gente não vai. A gente é tratada diferente porque a gente não pode, não sei o que. Daí falam muito a APAM, a APAM.

Elza- Às vezes tá todo mundo quieto na sala, daí eles entram e chamam (adolescente disse que chamam pelo nome e depois falam APAM), daí todo mundo fica olhando para a gente. Parece que eles tratam a gente de um jeito diferente.
\end{abstract}

As adolescentes da APAM expressam através de suas falas as experiências de bullying na escola. Esse espaço público, comum a todos, em que surgiu a RS, é o solo essencial e as abastece enquanto lugar de alteridade (JOVCHELOVITCH, 2011). Dessa maneira, as RS se constroem na medida em que haja fatos a explicar, problemas a resolver. Ao mesmo tempo, permite que o estudo organize-se em saberes num movimento dialético e dialógico. Jodelet (2001, p. 21) afirma que as RS são “[...] fenômenos complexos sempre ativados e em ação na vida social". Nesta direção, salienta-se que as falas das adolescentes expõem a relação e interação com os professores e pedagogas pautadas na "alteridade de fora” (JODELET, 1998), a qual traz a diferença da cultura, de seu contexto sócio-histórico de vulnerabilidade social, o estranho e ameaçador (MOSCOVICI, 2011).

Com base nas falas das adolescentes, obteve-se que professoras (es) e pedagogas(os) elaboraram nas relações e interações do cotidiano escolar os estereótipos baseados no estigma, rotulando ou apelidando as adolescentes da APAM, como base na diferença. Assim sendo, o "eu" se anula no açude simbólico de inúmeras e diferentes configurações para romper com a alteridade dos estigmatizados.

Nesse sentido, o estigma traz um pensamento com um caráter absoluto mediante as categorias biológicas evidenciando as diferenças; essas justificam a submissão, a exclusão e algumas vezes a eliminação do outro, "a alteridade de fora" que se torna constante, advindo

\title{
POLÊM!CA $\mid$ LABORE
}

Polêmica - Revista Eletrônica da Uerj - Rua São Francisco Xavier, 524, $1^{\circ}$ andar

bloco D, sl.1001 • Tels.: +55 21 2334-4088/4087 • http://www.e-publicacoes.uerj.br/index.php/polemica/index

http://www.labore.uerj.br • laboreuerj@yahoo.com.br 
em seguida à alteridade radical. O presente estudo aponta que o estigma ou atributo/rótulo recebido e vivenciado pelas adolescentes acolhidas não é o biológico, mas de sua condição social de vulnerabilidade social e risco. Essa condição determina o rótulo e o atributo depreciativo (GOFFMAN, 1988), a categorização (JODETET, 1998), e com isso, advém uma identidade social estigmatizada que destrói atributos e qualidades das alunas/adolescentes acolhidas, controlando suas ações, com ênfase nos desvios e escondendo o caráter ideológico dos estigmas.

\section{Conclusão}

O presente estudo buscou entender quais são as Representações Sociais (RS) que as adolescentes acolhidas na Marillac e na APAM possuem em relação à escola. Para isso, mediante o desenvolvimento do GF, obtiveram-se resultados significativos em relação às RS dessas adolescentes. As representações sociais são "fenômenos complexos" que são ativados continuamente na vida social, e se manifestam em situações de comunicação (JODELET, 2001; MOSCOVICI, 2011), por isso, utilizou-se a técnica do GF. Esta cria um espaço de conversação onde as representações sociais das adolescentes acolhidas podem se manifestar de forma natural, diminuindo a necessidade de interferência e direcionamento para fluir o diálogo.

No contexto estudado, as adolescentes acolhidas apresentaram múltiplas representações do cotidiano, tanto da escola como do acolhimento. Essas se encontram interligadas e são influenciadas reciprocamente, devido às circunstâncias sócio-históricas de risco e vulnerabilidade social vivenciadas pelas adolescentes. Os resultados permitiram analisar a Teoria das Representações Sociais (TRS) juntamente com contexto sócio-histórico (plano subjetivo) e o cotidiano das adolescentes acolhidas, que está ligado ao bullying, estigma e a alteridade radical, e ainda aos aspectos emocionais e afetivos das mesmas. Baseando-se nas falas das adolescentes da Marillac e da APAM, percebeu-se que as relações e interações escolares da maioria estão voltadas para os amigos (as), os quais possuem grande influência na vida das adolescentes, principalmente no cotidiano vivenciado na escola.

A dificuldade principal apresentada pelas adolescentes das duas instituições está em torno da relação e interação com os professores e equipe pedagógica na escola. Nessas relações ficaram evidentes as práticas de bullying, estigma e a alteridade radical. Estes

\section{POLÊM!CA $\mid$ LABORE}


apresentam consequências negativas para as adolescentes na escola e na vida social, afetandoas emocional e psicologicamente, influenciando, assim, a construção da identidade das mesmas. Neste sentido, compete à sociedade e ao Estado buscar nas políticas públicas e sociais propostas eficientes e eficazes, com um entendimento multisetorial e um trabalho interdisciplinar em rede, para averiguar outros aspectos relacionados, sejam direta ou indiretamente, a esses fenômenos, os quais estão interligados, encontrados nesta pesquisa. As políticas públicas e sociais devem ser conduzidas, na contemporaneidade, para atender as demandas específicas destas adolescentes e não da economia capitalista, pois as RS aqui destacadas estão presentes na vida cotidiana das adolescentes acolhidas, nas relações e interações, em meio aos mitos (com relação ao acolhimento) e sistemas presentes na sociedade.

\section{Referências}

AGUIAR, W. M. J. A pesquisa em psicologia sócio-histórica: contribuições para o debate metodológico. In: AGUIAR, W. M. J. et al. Psicologia sócio-histórica: uma perspectiva crítica em psicologia. 5. ed. São Paulo: Cortez, 2011. p. 129-140.

BARDIN, L. Análise de conteúdo. 7. ed. São Paulo: LDA Almedina, 2011. 279p.

BATISTA, E. H. M.; ALMEIDA, T. L. Crianças e adolescentes abrigados e a violência velada na escola: desafios e possibilidades. Revista Educação e Cidadania, v. 10, n. 10, p. 1-13, 2008.

BRASIL. Tipificação Nacional de Serviços Socioassistenciais. Resolução CNAS nº 109, de 11 de novembro de 2009. Brasília: MDS, 2009.

Política Nacional de Assistência Social - PNAS/2004; Norma Operacional Básica - NOB/Suas. Brasília: Ministério do Desenvolvimento Social e Combate à Fome - Secretaria Nacional de Assistência Social, 2005.

BRITO, J. M.; VEIGA, M. M. Variação da Vulnerabilidade Social no município de Belo Horizonte Pósimplantação do programa BH cidadania. Disponível em: <http://www.webartigos.com/artigos/variacao-davulnerabilidade-social-no-municipio-de-belo-horizonte-pos-implantacao-do-programa-bh-cidadania/132526/> . Acesso em: 05 out. 2016.

BOCK, A. M. B. A adolescência como construção social: estudo sobre livros destinados a pais e educadores. Revista Semestral da Associação Brasileira de Psicologia Escolar e Educacional (ABRAPEE), Porto Alegre, v.II, n. I, p. 63-76, jan./ jun. 2007.

FERRARI, M.; KALOUSTIAN, S. M. Introdução. In: KALOUSTIAN, S. M.(Org.). Família Brasileira: a base de tudo. 6. ed. São Paulo: Cortez, 2004.

GABATZ, C. Reflexões sobre exclusão e vulnerabilidade social no Brasil contemporâneo. Revista Sociedade em Debate, v. 21, n.1, p. 33-49, 2015.

GATTI, B. A. Grupo focal nas pesquisas em ciências sociais e humanas. Brasília: Líber Livro, 2005. 77p.

\section{POLÊM!CA $\mid$ LABORE}

Polêmica - Revista Eletrônica da Uerj - Rua São Francisco Xavier, 524, $1^{\circ}$ andar

bloco D, sl.1001 • Tels.: +55 21 2334-4088/4087 • http://www.e-publicacoes.uerj.br/index.php/polemica/index http://www.labore.uerj.br • laboreuerj@yahoo.com.br 
GIL, Antonio Carlos. Métodos e Técnicas de Pesquisa Social. 5. ed. São Paulo: Editora Atlas S.A, 1999. 206p.

GOFFMAN, E. Estigma: notas sobre a manipulação da identidade deteriorada. 4. ed. Rio de Janeiro: LTC, 1988. $158 \mathrm{p}$.

GONÇALVES, A. S.; GUARÁ, I. M. F. R. Redes de proteção social na comunidade, Por uma nova cultura de articulação e cooperação em rede: Uma convivência grupal que mobiliza, protege e desenvolve seus participantes. In: GUARÁ, I. M. F. R. (Coord.). Rede de proteção social. São Paulo: Associação Fazendo História: NECA- Associação dos pesquisadores de Núcleos de Estudos e Pesquisas sobre a criança e o Adolescente, 2010. 96p. (Coleção abrigos em Movimento).

GUARÁ, I. M. F. R. Abrigo: comunidade de acolhida e socioeducação. In: BAPTISTA, M. V. [coord.] Abrigo: comunidade de acolhida e socioeducação. São Paulo: Instituto Camargo Corrêa, 2006. 99p.

HELLER, A. O cotidiano e a história. 7. ed. São Paulo: Paz e Terra, 2004. 121p.

HILLESHEIM, B.; CRUZ, L. R.. Risco, Vulnerabilidade e Infância: algumas aproximações. In: CRUZ, L. R.; GUARESCHI, N. (Org.). Políticas Públicas e assistência social: diálogo com as práticas psicológicas. 5. ed. Rio de Janeiro: Vozes, 2014. p. 70-85.

IBGE. Síntese do município de Ponta Grossa Paraná. Disponível em:

<http://www.cidades.ibge.gov.br/v3/cidades/municipio/4119905>. Acesso em: 02 mar. 2017.

JODELET, D. A alteridade como produto e processo psicossocial. In: ARRUDA, A. (Org.). Representando a Alteridade. Rio de Janeiro: Vozes, 1998, p.47-67.

Representações Socais: um domínio em expansão. In: As representações sociais. Rio de Janeiro: Editora UERJ, 2001.

JOVCHELOVITCH, S. Vivendo a vida com os outros: intersubjetividade, espaço público e representações sociais. In: GUARESHI, P. A; JOVCHELOVITCH, S.(Org.). Textos em representações sociais. 12. ed. Petrópolis, Rio de Janeiro: Vozes, 2011. p. 53-72.

LIBÂNEO, J. C. O dualismo perverso da escola pública brasileira: escola do conhecimento para os ricos, escola do acolhimento social para os pobres. Revista e Pesquisa. São Paulo. v. 38, n.1, p. 13-28, 2012.

Políticas educacionais no Brasil: Desfiguramento da Escola e do conhecimento escolar. Cadernos de Pesquisa. v.46, n.159, p.38-62, jan./mar. 2016.

LÍRIO, L. C. A construção histórica da adolescência. In: Congresso Internacional da Faculdade EST,1., 2012, São Leopoldo. Anais... São Leopoldo. 2012. p. 1675-1688.

LOPES, J. R. Exclusão social, privações e vulnerabilidade. Revista em Perspectiva, São Paulo. v. 20, n.1, p. 123-135, jan./mar. 2006.

MOSCOVICI, S. Representações sociais: investigações em psicologia social. Petrópolis: Vozes, 2011. p. 7-109.

MONTEIRO, S. R. R. P. O marco conceitual da vulnerabilidade social. Revista Sociedade em Debate, São Paulo, v.17, n.1, p. 29-40, jul./dez. 2011.

ORNELLAS, M. L. Representação social do aluno na sala de aula e seu estilo no ato de aprender. Revista Educação \& Linguagem, v. 15, n. 25, p. 119-133, jan./jun. 2012.

\section{POLÊM!CA $\mid$ LABORE}

Polêmica - Revista Eletrônica da Uerj - Rua São Francisco Xavier, 524, $1^{\circ}$ andar bloco D, sl.1001 • Tels.: +55 21 2334-4088/4087 • http://www.e-publicacoes.uerj.br/index.php/polemica/index http://www.labore.uerj.br • laboreuerj@yahoo.com.br 
RAUCCI, M. M. Meninos de rua em São Paulo: socialização e sobrevivência. 2002. 394 f. Dissertação (Mestrado em Sociologia) - Faculdade de Filosofia, Letras e Ciências Humanas, Universidade de São Paulo, 2002.

SÁ, C. P. Representações Sociais: o conceito e o estado atual da teoria. In: SPINK, M. J. (Org.). O conhecimento no cotidiano: representações sociais na perspectiva da psicologia social. São Paulo: Brasiliense, 2004. p. 19-45.

SANTOS, M. A natureza do espaço: técnica e tempo, razão e emoção. 4. ed. São Paulo: EDUSP, 2006.384 p.

SANTOS, I. A. Diversidade na educação: uma prática a ser construída na Educação Básica. Disponível em: <http://www.diaadiaeducacao.pr.gov.br/portals/pde/arquivos/2346-6.pdf>. Acesso em: 08 jun. 2016.

SAWAIA, B. O sofrimento ético-político como categoria de análise da dialética exclusão/inclusão. In: (Org.). As artimanhas da exclusão: análise psicossocial e ética da desigualdade social. 2 ed. Petrópolis: Vozes, 2001. 97-118p.

SERIKAWA, F. M. A inclusão/exclusão escolar de crianças e adolescentes em acolhimento institucional. Brasília. 2015, 97f. Dissertação (Mestrado em Educação) - Universidade de Brasília, 2015.

SILVA SANTOS, Ana Sofia Carvalho. (In)Sucesso escolar de crianças e jovens institucionalizados. Dissertação de Mestrado. Instituto Superior de Ciências Sociais e Políticas da Universidade Técnica de Lisboa. Lisboa, 2009.

SOMER, D. G. As representações sociais das adolescentes acolhidas, na Casa Santa Luiza de Marillac e Associação de Promoção a Menina (APAM), em relação ao cotidiano escolar-Ponta Grossa/PR. 2017, 193f. Dissertação para obtenção do Título de Mestre (Ciências Sociais Aplicadas) - Universidade Estadual de Ponta Grossa, Ponta Grossa, 2017.

SOUZA, M. J. L. O território: sobre espaço e poder, autonomia e desenvolvimento. In: CASTRO, I. E. et al. (Orgs.). Geografia: Conceitos e Temas. Rio de Janeiro: Bertrand Brasil, 1995. p.77-116.

STEFAnO, I. G. A. Bullying na escola. Revista Âmbito Jurídico, Rio Grande, v. XVII, n. 124, p. 1-5, mai. 2014.

TOROSSIAN, S.D.; RIVERO, N. E. Políticas Públicas e Modos de viver: a produção de sentidos sobre a vulnerabilidade. In: CRUZ, L. R.; GUARESCHI, N. (Org.) Políticas Públicas e assistência social: diálogo com as práticas psicológicas. 5. ed. Rio de Janeiro: Vozes, 2014. p. 56-83.

Recebido em: 28/04/2017.

Aceito em: 30/01/2018.

\section{POLÊM!CA $\mid$ LABORE}

